УДК 539.2

\title{
Fragility, Tetragonality, Change the Morphology Martensite, Destabilization of Austenite with Carbon if it More than $\sim 0,5 \%$, as a Result of the Presence \\ of a Perceived Intermediate Phase $\sim \mathrm{Fe}_{42} \mathrm{C}$
}

\author{
Karen Y. Shakhnazarov* \\ National Mineral Resources University \\ (Mining University) \\ 2, 21st Line, St. Petersburg, 199106, Russia
}

Received 11.04.2016, received in revised form 13.06.2016, accepted 12.08.2016

Using analogies, descriptions, illustrations and quotations from the works of famous metallurgical scientists, an attempt was done to link tetragonality, fragility, changes in the morphology of the martensite, destabilization of austenite carbon when $\% C>(\sim 0,5 \%)$ with intermediate phase $\sim \mathrm{Fe} 42 \mathrm{C}(\sim 0,5 \% \mathrm{C})$. If \% C>0,5: martensite begins to change the morphology from dislocation to twin structure and become catastrophically fragile as well as becomes tetragonal without clasuse on smoothback during quench cooling; ferrite loses its ability to be widmanstatten and strengthen as a result of natural aging after subcritical quenching; the yield strength of ferrite-cementine mixture, regardless form of cementite, even begins to fall; the interval of martensite transformation starts to decrease, etc.

Keywords: austenite, martensite, intermediate phase, dislocation, alloy.

Citation: Shakhnazarov K.Y. Fragility, tetragonality, change the morphology martensite, destabilization of austenite with carbon if it more than $\sim 0,5 \%$, as a result of the presence of a perceived intermediate phase $\sim$ Fe $42 \mathrm{C}$, J. Sib. Fed. Univ. Eng. technol., 2016, 9(6), 912-917. DOI: 10.17516/1999-494X-2016-9-6-912-917.

(C) Siberian Federal University. All rights reserved

* Corresponding author E-mail address: karen812@yandex.ru 


\title{
Хрупкость, тетрагональность, изменение морфологии мартенсита, дестабилизация аустенита углеродом, если его болыше 0,5 \%, как следствия наличия предполагаемой промежуточной фазы $\sim \mathrm{Fe}_{42} \mathrm{C}$
}

\author{
К.Ю. Шахназаров \\ Нацииональный минерально-сырьевой университет «Горныйџ \\ Россия, 199106, Санкт-Петербург, \\ Васильевский остров, 21-я линия, 2
}

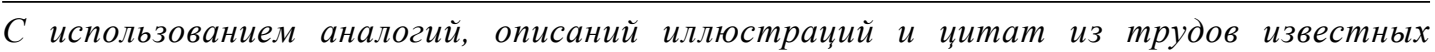
металловедов сделана попытка связать тетрагональность, хрупкость, изменение морфологии мартенсита, дестабилизацию аустенита углеродом при \% $C>(\sim 0,5 \%)$ с предполагаемой промежуточной фазой $\sim \mathrm{Fe}_{42} \mathrm{C}(\sim 0,5 \% \mathrm{C})$. При \% $\mathrm{C}>0,5$ мартенсит начинает менять морфологию от дислокационной к двойникованной, превращчаясь в катастрофически хрупкий, становится тетрагональным без оговорок на самоотпуск во время закалочного охлаждения; феррит теряет способность быть видманштеттовым и упрочняться в результате естественного старения после субкритической закалки; предел текучести ферритоцементитной смеси независимо от формы иеементита начинает даже понижаться; интервал мартенситного превращения начинает уменьшаться и т.n.

Ключевые слова: аустенит, мартенсит, промежуточная фаза, дислокация, сплав.

\section{Введение}

У нелегированного аустенита с 0,55 \% С максимумы электросопротивления и его температурного коэффициента при $1200{ }^{\circ} \mathrm{C}$ [1, с. 100], также максимумы твердости при 910 и $1000{ }^{\circ} \mathrm{C}$ [2, c. 1066$]$.

Комментарий к максимуму физических свойств таков: «Экстремальное поведение... нельзя объяснить изменением фазового состава» [1, с. 102].

Кривые с максимумом твердости описаны так: «В случае кратковременных испытаний твердость аустенита тем выше, чем больше в нем содержание углерода» [2, с. 1066]. И.И. Корнилов воспроизвел эти кривые [3, с. 218], но тоже не прокомментировал максимумы. Такая реакция на них в [2] и [3], возможно, связана с необычным (обескураживающим) влиянием углерода (примеси внедрения) на твердость твердого раствора (аустенита).

Полагаем, можно даже утверждать: максимумы (сингулярные точки на кривых состав свойство) являются признаками наличия промежуточных фаз. Это «Н.С Курнаков подчеркивал» $[4$, с. 62].

Поскольку «всеобъемлющей классификации промежуточных фаз на основе какого-либо единственного признака в настоящее время нет» [4, с. 56], то вторым выбран ФУНДАМЕНТАЛЬНЫЙ для конгруэнтно и инконгруэнтно плавящихся фаз признак - качественное изменение протяженности по температуре интервала кристаллизации по мере увеличения (уменьшения) содержания второго компонента $[4$, с. 57,64$]$. Этот признак в точке В (0,5 \% С) диаграммы $\mathrm{Fe}-\mathrm{Fe}_{3} \mathrm{C}$ из-за изгиба ликвидуса самоочевиден. (Подобных аустенитной высокотемператур- 
ных областей очень много, существует практика приписывания этим областям той или иной формулы, например $\mathrm{FeMo}, \mathrm{Fe}_{2} \mathrm{Te}_{3}$. Такие фазы, как и аустенит, образуются по перетектической реакции и распадаются эвтектоидно $[5$, с. 766,876$]$.)

Вряд ли влияние углерода на свойства аустенита представляет интерес для практики. Но аустенит является родительской фазой мартенсита. Хорошо известно, что структура первого наследуется вторым.

Цель настоящего обзора - попробовать обосновать связь структуры и свойств мартенсита с предполагаемой промежуточной фазой $\sim \mathrm{Fe}_{42} \mathrm{C}(\sim 0,5 \% \mathrm{C})$.

\section{Методика}

Предлагаемая концепция основана на взятых из общеизвестных источников описаниях иллюстраций, аналогиях и цитатах. Злоупотребление последними полагаем необходимым, чтобы направить внимание возможного читателя не на критику концепции, а на иное осмысление представленных материалов.

Подчеркнем: промежуточные фазы «обычно» - но не всегда - «имеют кристаллическую структуру, отличную от структуры компонентов» [4, с. 55].

\section{Обсуждение}

«Особенность мартенсита, выявляемая сравнением его с другими растворами внедрения, - слишком низкая пластичность. Вопрос о природе низкой пластичности закаленной стали - основной для практики» [6, с. 37]. «Основная причина резкого охрупчивания при закалке углеродистых сталей - малая подвижность дислокаций в мартенсите, содержащим углерод» [7, c. 226].

Между тем практика показала: «Применение высокопрочных сталей, содержащих более 0,43-0,45 \% С, вряд ли целесообразно» [8, с. 15]. При меньшем \% С, например, сталь 40ХГСН3ВА не уступает по вязкости равнопрочной $\left(\sigma_{\mathrm{B}}=2000 \mathrm{MПа)} \mathrm{безуглеродистой} \mathrm{стали} \mathrm{Н18К9М5Т} \mathrm{[8,} \mathrm{с.}\right.$ 133], которую во всех странах... выплавляют в вакуумных печах» [8, с. 116]. Высокочистые по сере и фосфору стали 38ХНМ и 38Х5МСФА при $\sigma_{\mathrm{B}} \sim 2000$ МПа имеют очень высокую вязкость на образцах с трещиной [9, с. 205].

Катастрофическую хрупкость мартенсита с \% C > 0,5 вряд ли можно связать с углеродом, так как, согласно С.3. Бокштейну, в интервале $0,4-0,7$ \% С практически не меняется «число элементарных ячеек мартенсита, на долю которых приходится по одному атому углерода» [10, с. 97]. В интервале $0,1-0,5$ \% С число таких ячеек уменьшается в пять раз.

Число элементарных ячеек подсчитано С.З. Бокштейном, чтобы обосновать причину неизменности твердости продукта закалки при \% C > 0,5 [10, с. 97].

Между тем неизменность твердости вблизи составов промежуточных фаз $\mathrm{Cu}_{3} \mathrm{Au}$ и $\mathrm{Pb}_{3} \mathrm{Na}$ показана Р.С. Курнаковым, как и хрупкость, например, фазы FeAl 3 [11, с. 39, 469, 546]. Это позволяет связать - по аналогии - хрупкость и неизменность твердости мартенсита с \% C > 0,5 c наличием промежуточной фазы $\sim \mathrm{Fe}_{42} \mathrm{C}(\sim 0,5 \% \mathrm{C})$.

Отметим также, что вблизи состава фазы $\mathrm{FeAl}_{3}$ электросопротивление и его температурный коэффициент практически неизменны [11, с. 543], как и твердость мартенсита [10, с. 543] вблизи предполагаемой фазы $\sim \mathrm{Fe}_{42} \mathrm{C}$. 
Неизменность твердости (на пяти кривых [12, с. 192, 193]) продукта закалки с \% C > 0,5 вряд ли связаны с остаточным аустенитом, так как при его содержании $21 \%$ твердость максимальна ( HRC 65) [12, с. 210].

Утверждение «тетрагональность мартенсита - прямое следствие содержания в растворе углерода» [13, с. 191] может выглядеть сомнительно в свете следующих наблюдений Г.В. Курдюмова с соавторами: «Термодинамический анализ показывает, что теоретически возможно распределение атомов углерода... только в одной подрешетке решетки с тетрагональной симметрией, так и неупорядоченное распределение по всем подрешеткам в решетке с кубической симметрией» [9, с. 56]; «Можно было ожидать, что перемещение атомов углерода к дислокациям должно сопровождаться изменением периодов тетрагональной решетки мартенсита... однако обнаружить эти изменения... пока не удалось» [9, с. 121]; «Проведенное на монокристаллах железоникелевых сталей... с точкой $\mathrm{M}_{\mathrm{H}}$ около минус $35{ }^{\circ} \mathrm{C}$ показало, что... образуется мартенсит с тетрагональной решеткой даже при очень низких содержаниях углерода» [9, с. 55].

Вблизи минус $35^{\circ} \mathrm{C}$ находится $\mathrm{M}_{\mathrm{H}}$ безуглеродистого сплава с $\mathrm{Fe}+\sim 28 \% \mathrm{Ni}[12$, с. 602]. Таким образом, тетрагональность мартенсита этого сплава может быть связана с фазой $\sim \mathrm{Fe}_{3} \mathrm{Ni}$. Необходимость учета этой фазы при обсуждении природы железоникелевого мартенсита подчеркивал Г.В. Курдюмов с соавторами [9, с. 115]. Тогда - по аналогии - тетрагональность углеродистого мартенсита может быть связана с фазой $\sim \mathrm{Fe}_{42} \mathrm{C}$.

К такой аналогии подталкивает учебник [7, с. 208], в котором со ссылкой на Крауса и Мадера изменение морфологии мартенсита от дислокационной к двойникованной при $\sim 0,6 \% \mathrm{C}$ (в углеродистых сталях) и при $\sim 27$ ат. \% Ni (в железоникелевых сплавах) рассматривается совместно.

Самым существенным, на наш взгляд, является следующее. Фаза $\mathrm{Fe}_{3} \mathrm{Ni}$ была декларирована в 1939 г. [5, с. 815], но в отличие от Г.В. Курдюмова с соавторами ее не признает большинство исследователей [5, с. 785], включая Э. Гудремона [12]. Но последний показывает уникальность сплава $\mathrm{c} \sim 25 \% \mathrm{Ni}$ - совершенную независимость от температуры коэффициента линейного расширения при $\left(100-900{ }^{\circ} \mathrm{C}\right)$ : все 9 кривых пересекаются в одной точке с абсциссой $25 \% \mathrm{Ni}$ [12, с. 661]; инвару далеко до этого сплава по постоянству коэффициента расширения.

На восьми кривых отчетливый максимум при $\sim 25 \% \mathrm{Ni}$ электросопротивления, измеренного при $0-1000{ }^{\circ} \mathrm{C}[5$, с. 807]. Введение $~ 25 \% \mathrm{Ni}$ скачкообразно повышает коррозионную стойкость железа в 40 раз; из этого сплава делали корпуса лодок, перископы, торпеды [12, с. 634].

Как известно, промышленность потребляет не структуру, а свойства. Непризнание фаз $\mathrm{Fe}_{3} \mathrm{Ni}$ и $\mathrm{Fe}_{42} \mathrm{C}$ не отменяет аномалий свойств, например катастрофическую хрупкость заведомо обязанного быть пластичным твердого раствора (мартенсита с \% C > 0,5). Аппеляции к подвижным во время испытаниям «охрупчиващим» атомам углерода вряд ли уместны - равнопрочные с углеродистыми безуглеродистые мартенситно-стареющие стали с интерметаллидным упрочнением имеют примерно тот же уровень пластичности и вязкости [8, с. 133].

Утверждение, что «углерод интенсивно снижает температуру начала и конца мартенситного превращения», не соответствует рисунку: под влиянием углерода $\mathrm{M}_{\mathrm{H}}$ действительно понижается почти линейно, но при \% C > 0,6 М К почти перестает зависеть от \% C [13, с. 195]. С учетом всех экспериментальных точек (а не кривой $\mathrm{M}_{\mathrm{H}}$, проведенной мимо них [13, с. 195]) это означает, что при $\sim 0,5 \%$ С интервал перекристаллизации $\mathrm{M}_{\mathrm{H}}-\mathrm{M}_{\mathrm{K}}$ максимален, т.е. ста- 
бильность аустенита против превращения в мартенсит максимальна. (Отметим, что интервал кристаллизации у инконгруэнтно плавящейся фазы максимален [4, с. 64].)

Увеличение \% С выше $\sim 0,5$ сужает интервал $\mathrm{M}_{\mathrm{H}}-\mathrm{M}_{\mathrm{K}}$ [13, с. 195], то есть дестабилизирует аустенит.

Максимальный интервал $\mathrm{M}_{\mathrm{H}}-\mathrm{M}_{\mathrm{K}}$ при $~ 0,5$ \% С означает затруднение превращения аустенита в мартенсит. Так же «затрудняет образование мартенситной структуры» сверхструктура $\mathrm{Fe}_{3} \mathrm{Pt}\left[5\right.$, c. 836], что является доводом - по аналогии - для признания структуры $\mathrm{Fe}_{42} \mathrm{C}$. (При высокой подвижности углерода упорядочение может проходить даже во время закалочного охлаждения.)

Среди доэвтектоидных сталей, закаленных в воду или жидкий азот, у стали с 0,5 \% C локальный максимум модуля Юнга [14, с. 232]. Этот экстремум (сингулярная точка) является формальным основанием для признания промежуточной фазы $\sim \mathrm{Fe}_{42} \mathrm{C}$. Но, возможно, экстремум связан с разной генеалогией атомов железа левее и правее точек В и О $(0,5 \%$ С): расплав $\rightarrow \delta \rightarrow \gamma \rightarrow \beta \rightarrow \alpha$ и расплав $\rightarrow \gamma \rightarrow \alpha$ соответственно

Значение генеалогии подчеркивал Э. Гудремон [12, с. 792], связывая с ней резкие изменения свойств, включая коррозионную стойкость [12, с. 789, 792, 802, 814], всегда ферритных при $20{ }^{\circ} \mathrm{C}$ сплавов $\mathrm{Fe}-\mathrm{Cr}$ левее и правее $12-13 \% \mathrm{Cr}$, когда замыкается $\gamma$-область. Но есть и иная версия - аномалии свойств могут быть связаны со сверхструктурой $\mathrm{Fe}_{7} \mathrm{Cr}$ [5, с. 940].

Тогда - по аналогии - упомянутые изменения структуры и свойств мартенсита можно связать со сверхструктурой $\sim \mathrm{Fe}_{42} \mathrm{C}$.

\section{Заключение}

Все приведенные экспериментальные данные и суждения взяты из трудов известных металловедов. Предложенное их толкование может представляться сомнительным, как сомнительны «успехи» в постижении высокой прочности мартенсита - «вклад каждого из факторов в общее упрочнение при закалке окончательно не установлен» [7, с. 225]. Это предполагает возможность открытой дискуссии, а не следование стереотипам.

Формальное хотя бы признание фазы $\sim \mathrm{Fe}_{42}$ С делает символ промежуточной фазы - вертикаль при 0,5 \% С, проведенную Д.К. Черновым 10.11.1916 [13, с. 114], - оправдавшейся «гениальной догадкой» (Ф. Энгельс. Происхождение семьи, частной собственности и государства).

Возможно, удастся определить структуру фазы $\mathrm{Fe}_{42} \mathrm{C}$, хотя М. Хансен считал: «Промежуточная фаза может обладать выраженными химическими свойствами, подобными свойствам типичных соединений, не будучи по характеру своей кристаллической структуры соединением» $[15$, с. 377$]$.

Есть соблазн считать М. Хансена «устаревшим», как и диаграмму Д.К. Чернова с вертикалью при 0,5 \% С. Это противоречит наставлению А.А. Бочвара студентам: «Нельзя сделать общее заключение о большой верности новых диаграмм» [16, с. 194].

\section{Список литературы}

[1] Баум Б.А., Хасин Г.А., Тягунов Г.В. и др. Жидкая сталь. М.: Металлургия, 1984. 208 с. [Baum B.A., Hasin G.A., Tyagunov G.V. i dr. Liquid steel. Moscow, Metallurgiya, 1984, 208 p. (in Russian)] 
[2] Осипов К.А., Мирошкина Е.М. Твердость $\gamma$-твердого раствора системы железо-углерод при высоких температурах. Журнал ДАН СССР, 1954, Т, 94, № 6, 1065- 1067 [Osipov K.A., Miroshkina E.M. Hardness of $\gamma$-system solid solution iron-carbon at high temperatures, J. DAN USSR, 1954, T. 94, N6, 1065-1067 (in Russia)]

[3] Корнилов И.И. Физико-химические основы жаропрочности сплавов. М.: Изд-во АН CCCP, 1961. 516 c [Kornilov I.I. Physical and chemical bases of hot-resistance of alloys. Moscow, Izdvo AN SSSR, 1961, 516 p. (in Russia)]

[4] Захаров А.М. Диаграммы состояния двойных и тройных систем. М.: Металлургия, 1961. 240 c [Zaharov A.M. Diagrams of the state of the double and triple systems, Moscow, Metallurgiya, 1961, 240 p. (in Russia)]

[5] Вол А.Я. Строение и свойства двойных металлических систем. В 4-х т. Т.2. М.: Гос. Изд-во физ-мат. лит-ры, 1962. 982 с. [Vol A.Y. Structure and properties of the double metallic systems. Moscow, Gos. Izd-vo fiz-mat. lit-ry, 1962. 982 p. (in Russia)]

[6] Штремель М.А. Строение и прочность твердых растворов внедрения. М.: Машиностроение, 1973. 40 с. [Shtremel M.A. The structure and strength of solid solutions of introduction. Moscow, Mashinostroenie, 1973. 40 p. (in Russia)]

[7] Новиков И.И. Теория термической обработки металлов. М.: Металлургия, 1978. 392 с. [Novikov I.I. Theory of heat treatment of metals. Moscow, Metallurgiya, 1978, 392 p. (in Russia)]

[8] Потак Я.М. Высокопрочные стали. М.:Металлургия, 1972. 208 с.[Potak Y.M. Highstrength steel. Moscow, Metallurgiya, 1972, 208 p. (in Russia)]

[9] Курдюмов Г.В., Утевский Л.М., Энтин Р.И. Превращение в железе и стали. М.: Наука, 1977. 236 c. [Kurdumov G.V., Utevski L.M., Entin R.I. Conversion of the iron and steel. Moscow, Nayka, 1977, 236 p. (in Russia)]

[10] Мороз Л.С. Тонкая структура и прочность стали. М.: Металлургиздат, 1957. 159 с. [Moroz L.S. The fine structure and the strength of steel. Moscow, Metallyrgizdat, 1957, 159 p. (in Russia)]

[11] Курнаков Н.С. Избранные труды. В 3-х т. Т.2. М.: Изд-во АН СССР, 1961. 611 с. [Kyrnakov N.S. Selected works. Moscow, Izd-vo AN SSSR, 1961, 611 p. (in Russia)]

[12] Гудремон Э.С. Специильные стали. В 2-х т. Т1. М.: Металлургиздат, 1959. 952 с. [Gydremon Y.S. Special steels. Moscow, Metallyrgizdat, 1959, 952 p. (in Russia)]

[13] Гуляев А.П. Металловедение. М.: Металлургия, 1968. 480 c. [Gylyev A.P. Metallographye. Moscow, Metallurgiya, 1968, 480 p. (in Russian)]

[14] Самарин А.М., Федотов С.Г., Федотов В.П., Синодова Е.П. Структура и свойства сплавов железа с углеродом. Металловедение: Материалы симпозиума по металлургии и металловедению, посвященного 100-летию открытия Д.К.Черновым полиморфизма железа. М.: Наука, 1971. C. 231-235 [Samarin A.M., Fedotov S.G., Fedotov V.P., Sinodova E.P. The structure and properties of iron-carbon alloys, Mat. simp., Moscow, Nayka, 1971, 231-235 (in Russian)]

[15] Хансен М. Структуры бинарных сплавов. В 2-х т. Т.1 М., Л.: Металлургиздат, 1941. 640 c. [Hansen M. The structures of binary alloys. Moscow, Metallyrgizdat, 1941, 640 p. (in Russia)]

[16] Бочвар А.А. Металловедение. М.: Металлургиздат, 1956. 495 с. [Bochvar A.A. Metallographye. Moscow, Metallyrgizdat, 1956, 495 p. (in Russia)] 